\title{
JOVELLANOS Y LA POESÍA BURGUESA
}

\author{
Y pues que no me es dado que presuma \\ alcanzar por mis versos alto nombre, \\ dejadme al menos en tan noble intento \\ la gloria de guiar por la ardua senda \\ que va a la etema fama, vuestros pasos. \\ $\left(B A E\right.$, t. $4^{6}$, p. $\left.3^{8 b}\right)$.
}

La literatura dieciochesca es quizá una de las pruebas decisivas del paternalismo liberal de la España ilustrada. Como lo han señalado Sánchez Agesta y Morodo ${ }^{1}$, este paternalismo es el signo más acusado del aristocratismo que se refleja en la estructura política de la época. El siglo descubre al pueblo, pretende educarlo. Los reformadores ilustrados lo ven con una mezcla de cariño y desprecio. Lo sienten distinto. Quieren para él, ciertamente, educación y reforma, pero temen darle poder (de ahí que políticamente, como ha observado Morodo, estén fuera del liberalismo). Su pensamiento, más que contra-revolucionario, es anti-revolucionario ${ }^{2}$. Defienden la tradición (monarquía absoluta) y ven con recelo la democracia. Esta generación tradicionalista $^{3}$ rechaza cualquier tipo de planteamiento liberal y

1 Luis Sánchez Agesta, El pensamiento politico del despotismo ilustrado, Madrid, 1953; Raúl Morodo, "La reforma constitucional de Jovellanos y Martínez Marina”, $B I S D$, ı 963 , núms. 29/3o, pp. 79-93.

2 Moropo, art. cit.-El gobiemo y la orientación de Carlos III son muy revolucionarios de primera intención, pero hacia 1766 , con el motín de Esquilache, esto cambia, y en adelante habrá más cautela. Cf. el valioso libro de Vicente Ronriguez Casado, La politica y los politicos en el reinado de Carlos III, Madrid, 1962, especialmente pp. 43-46. Por otra parte, la Revolución francesa convertirá a muchos de los ilustrados en antirrevolucionarios. (Los Diarios de Jovellanos son muy reveladores a este respecto). Se puede observar que comienzan a surgir poemas anti-revolucionarios en i 793 -guerra anti-rousseauniana y anti-lockiana a la cual se unieron todos. Morodo no señala con claridad estos cambios de orientación que padecen los ilustrados. Véase también Vicente Llorens, "Jovellanos y Blanco. En torno al Semanario Patriótico de i 809 ", NRFH, i5 (196i), 267-278, que habla agudamente del "ilustre grupo de aquellos reformadores del despotismo ilustrado a quienes la sacudida de la Revolución francesa, tan opuesta a su sentido reformador, hizo profundamente anti-revolucionarios" (p. 273).

3 A primera vista, este tradicionalismo puede chocarnos y parecernos elemento antiburgués. Pero si estudiamos detenidamente los poemas y las cartas de Jovellanos a los escritores de su época, y en especial la epistola $A$ sus amigos de Salamanca, veriamos que el camino que le muestra a Meléndez Valdés es el de 
radical: se opone, por ejemplo, al liberalismo rousseauniano del Contrato social, y lo considera como la expresión máxima de la subversión jurídica. Junto a lo que se publica para el lector ignorante, está lo que sólo se confía a los amigos "ilustrados". El pueblo es sujeto pasivo. Aunque existe interés por lo popular, y hasta por los problemas sociales de la clase campesina, no hay sino censura para el pueblo de la corte, para la plebe ignorante ${ }^{4}$. El pueblo es siempre algo distante. El vocabulario con que se refieren a él los intelectuales es muy revelador: "vulgo", "estólida chusma", "chusma afligida", "vulgo necio", "plebe engañada"...

Existe, aparentemente, una contradicción entre el aristocratismo y el sentimiento burgués del grupo reformador. Hay que recordar que el burgués del siglo xvirr se ha educado a lo monárquico; que es monárquico por tradición y formación. Como ha observado Laski a

una poesía patriótica que ensalce a los héroes nacionales. En cierta medida este tradicionalismo tiende al nacionalismo. Jovellanos desea crear conciencia de pueblo en el español y recordarle sus gestas gloriosas. Sobre la aparente oposición entre el sentimiento liberal y el absolụtismo dice SÁnchez Agesta, op. eit., p. 99: "Este pensamiento, en su corriente genuinamente enciclopedista, no fue liberal ni demócrata, sino que al mismo tiempo se manifiesta externamente como la máxima exaltación del despotismo monárquico. Puede parecer una paradoja, pero tal es el hecho evidente de la historia". Según Antonio Domínguez Ortiz, La sociedad española en el siglo xviii, Madrid, 1955, pp. 395-396, a los intelectuales de la Ilustración "se les puede acusar de haber utilizado el absolutismo monárquico a guisa de instrumento para la realización de sus ideas, de haber apartado cuidadosamente al pueblo de toda participación en el gobierno y de haber hecho posible el anacrónico despotismo palatino de Godoy". Más ponderado, JEAN SARrailh, La España ilustrada en la segunda mitad del siglo xviii, trad. A. Alatorre, México, 1957, pp. 186-187, dice: “¿Pensaban acaso [los españoles ilustrados] de manera distinta que los franceses? No lo creemos. En primer lugar, para enriquecer a España, reclaman las técnicas científicas, únicas capaces de salvar de la miseria a sus artesanos y a sus labradores y de devolverle la prosperidad, preocupación esencial de Carlos III y de sus ministros y consejeros... Pero saben igualmente que la cultura nueva liberará a su país de sus cadenas espirituales, del yugo aplastante de la filosofía escolástica, del principio de autoridad que se ríe de los hechos y de la razón. Y esta convicción, secreta o manifiesta, de su doble papel bienhechor, como también la importancia casi mística que se le concede, es lo que explica que poco a poco se haya venido a considerar esa cultura como un servicio del Estado y haya venido a ser -perdónesenos el anacronismo- una «cultura dirigida"... Como Ward, muchos españoles estiman que la cultura debe estar dirigida por el poder central y que no puede confiarse a la iniciativa privada e individual".

4 Los signos de aristocratismo se descubren por todas partes. Feijoo, por ejemplo, desconfía sistemáticamente del público, del "vulgo" o "turba ignorante". Hay lo que ha llamado Sánchez Agesta, op. cit., p. go, una "relación pedagógica" con el pueblo, a quien se descubre como sujeto pasivo de una educación nacional. Este hecho no es sino consecuencia de la actitud de recelo (y, si se quiere, desprecio) frente a la "ignorancia" del pueblo, que es una constante tanto en los discursos de Feijoo contra los errores comunes como en el énfasis poético con que Jovellanos enfrenta los sabios al "vulgo idiota". 
propósito de Francia, no hay razón para pensar que los filósofos formaran una sociedad organizada que compartía un cuerpo común de ideas integradas ${ }^{5}$. La época es de terrible confusión. Cada pensador siente los contrastes, pero no sabe con coherencia lo que habría que hacer. Lo que sí va viendo con claridad cada vez mayor es el camino hacia la prosperidad: el que conduce a perfeccionar la legislación, adelantar la ilustración y conseguir la riqueza de los españoles (cf. $B A E$, t. 86 , p. 198 ). Se trata, pues, de un liberalismo engarzado en la economía. Uno de los historiadores que mejor han explicado esta contradicción inherente al intelectual del siglo xvirr es Rafael Altamira, que expone el pensamiento del despotismo ilustrado como idea caracterizada por un marcado interés en los problemas que se refieren a la mejora de las condiiciones económicas, sociales y culturales: restauración de la riqueza general y de la hacienda ${ }^{6}$, fomento de la población y del cultivo del suelo, renacimiento de las industrias tradicionales y de las relaciones mercantiles, y por otro lado la tendencia a reconocer el valor social de las clases inferiores, el afán de difundir la cultura y arrancar a la masa del estado de ignorancia en

5 Harold J. Laski, El liberalismo europeo, trad. V. Miguélez, México, 1961, p. 142.-Recuérdese que la política de Carlos III tendía a disminuir los poderes de la nobleza, sustituyéndola por miembros de la burguesía. Pero a pesar de esta transformación radical coexistían en su gobierno los hombres del antiguo régimen y los de la burguesía. De hecho, la administración de Carlos III, más que por un ideal burgués, se caracteriza por una marcada tendencia anti-aristocrática. La política de la monarquía no se encamina a promover el auge de la burguesía, sino a debilitar las fuerzas aristocráticas del. antiguo régimen (Cf. Rodríguez Casado, op. cit, passim, y el interesante opúsculo de V. Palacio Atard, Fin 'de la sociedad española del antiguo régimen, Madrid, r96r).-SÁNCHez Agesta, op. cit., p. 4o, subraya excesivamente el antitradicionalismo de los ilustrados: "Philomodernos y xenófilos (si se nos permite usar de la fábrica de Cadalso), todos ios escritores del xvmr, casi sin excepción, abominaron todo lo antiguo y desheredaron todo lo español". Domínguez OrTiz, op. cit., pp. $3^{8} 5^{-}$ 391, habla también de una denigración del pasado en el pensamiento del siglo xvrn. Yo me inclino a pensar, con Sarrailh, que no hubo rompimiento con la tradición española, aunque es verdad que la generación reformadora estaba en contra de quienes recreaban morosamente el pasado sin deseos de superarlo. El siglo xvin fue hacia la tradición con ánimos de quitarle su retórica, su hojarasca. En este sentido, como acertadamente observa Enrique Tierno Galván, Tradición y modernismo, Madrid, 1962, el siglo importa ideas de Francia e interpreta la tradición española con criterios europeos secularizados. Pero el español ilustrado sabe que está reanudando una tradición gloriosa y que continúa la obra de regeneración nacional de los grandes educadores y hombres de acción del siglo xvi. A mi juicio, la Ilustración española es continuadora: los mejores escritores de la época acuden siempre al Siglo de Oro y exaltan los valores del pasado.

6 Obsérvese la relación que hay entre estos postulados y los de las teorías económicas de Adam Smith y los fisiócratas franceses. Habría que estudiar la influencia de los grandes economistas europeos del siglo xvin en la Ilustración española. Meléndez, Quintana y Jovellanos, entre otros, los citan varias veces, sobre todo a partir de 1795 . 
que vive. Todo esto, combinado con el sentido filantrópico dominante en las ideas sociales, significa una especie de revolución desde arriba, y lleva en el fondo un incipiente sentimiento democrático que producirá sus efectos en el xix ${ }^{7}$.

Desprecio, pues, por los errores y supersticiones del vulgo, pero también afán de reforma y deseo ardiente de combatir las tradiciones caducas y anquilosadas que tenían oprimido al pueblo ${ }^{8}$. Pese a su desprecio, la élite ha aceptado un compromiso: el de "ilustrar". Tal es el vínculo que une a esta intelligentsia con el pueblo español. El medio más eficaz es la literatura.

La poesía, que hasta el siglo xvn estuvo regida fundamentalmente por un propósito artístico, recibe ahora la infusión del espíritu científico y de reforma. La literatura que canta el progreso de la humanidad, que propone como ideal al hombre libre guiado por los principios de su razón soberana, es necesariamente una literatura vinculada a la "filosofía" y al historicismo. Es el medio que mantiene la unidad entre las aportaciones científicas abstractas y la influencia de las ideas filosóficas sobre el gran público. Jovellanos lo dijo una y otra vez en sus discursos sobre la educación: "El principal objeto que se propone la poesía es agradar y conmover, aunque secundaria o indirectamente puede y debe tener la mira de instruir o corregir" (BAE, t. 46 , p. $137 b)$. Más claro aún: "Las ciencias [se emplean] en adquirir y atesorar ideas, y la literatura en enunciarlas; por las ciencias alcanzamos el conocimiento de los seres que nos rodean, columbramos su esencia, penetramos sus propiedades, y levantándonos sobre nosotros mismos, subimos hasta su más alto origen. Pero aquí acaba su ministerio, y empieza el de la literatura, que después de haberlas seguido en su rápido vuelo, se apodera de todas sus riquezas, les da nuevas formas, las pule y engalana, y las comunica y difunde, y lleva de una en otra generación" (ibid., p. $\left.33^{1} b\right)^{9}$.

Estos hombres ilustrados propugnan una estética al servicio de los ideales de la época. Sienten la realidad de manera distinta, al paso

7 Rafael Altamira, Historia de España y de la civilización española, Barcelona, 1929, t. 4, p. 143 .

8 "En los reformadores del siglo xvi y en los del xvrri se observa el mismo ardor por el estudio, el mismo entusiasmo por la difusión de los conocimientos útiles, el mismo afán del bien público. Los del siglo xvirr encuentran, en el ejemplo de sus predecesores, un motivo más para aumentar su confianza en esa cultura nueva que devolverá a España su antigua grandeza. Su generoso entusiasmo estalla en todas partes, en los periódicos que quieren llevar a todos los lectores las luces y las buenas nuevas, en las Sociedades económicas, propagadoras de las buenas técnicas y del progreso, generador de prosperidad, e incluso en la poesía y las bellas letras que celebran a porfía al artesano virtuoso, y se conmueven, con Cienfuegos, ante la figura del digno carpintero Alonso" (SARRAILH, op. cit., pp. 181-182).

9 Sobre el problema paralelo que se planteaba en Alemania, véase WiLHeLm Dilthey, De Leibniz a Goethe, trad. E. Ímaz, México, 1945, pp. 146-148. 
que se van quebrantando las formas y reglas existentes, y hasta se crean nuevas formas de arte (como en el caso del ensayo, tal y como lo inaugura Feijoo). Es una literatura que supedita la poesía al mundo de la razón. La materia poética está dominada por el convencionalismo. Los ilustrados quieren argumentar, refutar, persuadir. Jovellanos y sus amigos reclaman sin cansarse la cultura práctica. Ésta se les muestra como fuente de felicidad, puesto que todo lo que tiene un sentido utilitario servirá para el bien del pueblo. El fin supremo es la eficacia. De ahí que en esta "cultura dirigida" el Estado deba prohibir la publicación de obras groseras y dañosas. La literatura tiene finalidad inmediata: "Para comunicar la verdad es menester persuadirla, y para persuadirla, hacerla amable. Es menester despojarla del oscuro científico aparato, tomar sus más puros y claros resultados, simplificarla, acomodarla a la comprensión general e inspirarle aquella fuerza, aquella gracia que, fijando la imaginación, cautiva victoriosamente la atención de cuantos la oyen" $\left(B A E\right.$, t. $4^{6,}$ p. $\left.333^{a}\right)$.

Esta poesía está impregnada de optimismo. Sin romper con las tradiciones hispánicas, las enlaza, en cierta medida, al movimiento científico y progresista de utilidad. En España, como en otros países de Europa, el volumen de fuerzas se orienta hacia afuera: se fundan instituciones y se transforman las circunstancias sociales. La poesía adquiere, así, otro sentido. Tal será la aportación de Jovellanos: la poesía, como todas las expresiones artísticas, debe contribuir a la gran obra de restauración. No se intenta alterar el mundo interior para cuajar una existencia satisfecha. Desde luego que el redescubrimiento de la verdadera religión (la que buscan los hombres ilustrados) significa el regreso al cristianismo interior. Los reformadores aspiran a un mejoramiento moral, pero en concordancia plena con las ciencias modernas y la nueva filosofía. Reforma que restituya a los españoles los beneficios de la razón y de la virtud ${ }^{10}$.

El siglo comienza con una filosofía que aspira a un cambio total en la estructura de la sociedad, con métodos que le son propios. Es, pues, casi imposible estudiar los fenómenos aisladamente, segregados de su lógica y entrelazada organización. Pero esta filosofía, con todas las medidas prácticas que propone (reforma agraria y de la enseñanza,

10 Aunque no hubo reforma eclesiástica en España, sí la hubo en las conciencias de los ilustrados. Éstos no dan un paso más allá respecto de la autoridad de las Escrituras, pero se liberan de todo lo externo. No se pierde en fuerza religiosa, sino que, manteniéndose la religión como la esencia misma del hombre, el pensar racional cobra fuerza. La religiosidad, el mundo interior, cede el paso al mundo secularizado. A veces, los temas de la grandeza de Dios y de la miseria del hombre se entremezclan con evocaciones brillantes del mundo misterioso e insondable de los astros. (Véanse los libros clásicos de Ernst Cassirer, Filosofia de la Ilustración, trad. E. fmaz, México, 1943, y de Bernhard GroeTHUYSEN, La formación de la conciencia burguesa en Francia durante el siglo xviii, trad. J. Gaos, México 1943). 
libertad de comercio, etc.), refleja un cambio social muy acusado y definido: el surgimiento de la burguesía, que había quedado trunca desde la época de los Reyes Católicos. Los ideales que va esbozando esta minoría son ideales burgueses, y la literatura propone y refleja esos mismos ideales.

Pero vale la pena señalar qué entendemos por burguesía. Creo que todos estaremos de acuerdo si definimos al burgués como al hombre que se basta a sí mismo, y cuyas raíces están en la experiencia misma de la vida; que sabe orientarse en el mundo, sabe que significa algo y quiere hacer valer sus peticiones acá abajo. La misma muerte pierde, para el burgués, mucho de su misterio: comienza a despojarse de sus características religiosas ${ }^{11}$; es una especie de sentir sin creer. La vida, por el contrario, pierde su sentido negativo. El burgués sabe para qué vive; su vida tiene una finalidad aquí abajo.

El burgués español del siglo xviı es optimista. No es, como el hombre del antiguo régimen, un conformista, y tampoco es verdaderamente pesimista en cuanto al porvenir de su patria. Cree en la renovación por medio de las nuevas fórmulas que preconiza. Confía en sus fuerzas y en su trabajo, y sobre todo en las "luces", de donde vendrá el remedio de todos los males. Es eminentemente pacifista. Le repugna la guerra por inhumana y antisocial. Su ideal es una era de paz en que la libre comunicación de ideas y luces permita al país entrar decididamente por el camino del progreso. Se queja de que las fuerzas se empleen al servicio de la guerra que, atropellando los derechos, la propiedad y la libertad de los individuos, los envía a la muerte en vez de utilizarlos en una labor de pacífica productividad. $\mathrm{Si}$ es tanto lo que falta por hacer en el interior, ¿a qué lanzarse a empresas exteriores que acarrean la muerte o la ruina de los ciudadanos o que, en todo caso, entorpecen la reorganización interna de la nación? ${ }^{12}$

Está arraigado en este burgués el sentimiento de afirmación nacional, de confianza en su propia clase y en su capacidad de perfeccionamiento. Su protesta se alza contra el mal gobierno y contra las

11 Es curioso que apenas haya referencias a la muerte en la poesía española de la segunda mitad del siglo xvm.-Sobre las relaciones entre la religión y la burguesía cf. R. H. TAwney, Religion and the rise of capitalism, Penguin Books, 1942, p. 214: "When the age of the Reformation begins economics is still a branch of ethics, and ethics of theology... The secularization of political thought, which was to be the work of the next two centuries, had profound reactions on social speculation, and by the Restoration the whole perspective, at least in England, has been revolutionized".

12 Son muy reveladoras las cartas de Jovellanos a Godoy $(B A E$, t. 86, pp. 193-203), en las cuales le traza todo el programa de la Ilustración. Sobre el pacifismo, cf. p. 198b: “Lo diré de una vez? Un Gobierno ilustrado jamás emprenderá una guerra, jamás dejará de hacer los mayores esfuerzos para alejar su necesidad, y se puede pronosticar que su sabiduría le dará siempre medios oportunos para evitarla, y, por consiguiente, que nunca la tendrá". 
clases privilegiadas que explotan a un pueblo paciente y resignado, digno de un nivel de vida superior y, sobre todo, capaz de alcanzarlo, de conquistarlo. El burgués es el nuevo elemento social que se sabe poderoso y amenaza al antiguo orden, porque sus cauces le resultan estrechos. Es el hombre que mira con optimismo su país, porque cree en la propia perfectibilidad. Esgrime su censura contra el presente y preconiza una serie de reformas que traerán el bienestar en un próximo futuro. Es el hombre descontento cuyos postulados, una vez que se desarrollen, formarán el liberalismo. Su labor es crítica, pero él está demasiado vinculado al antiguo régimen para dar soluciones consecuentes con esta crítica ${ }^{13}$.

Obsérvese, finalmente, que este ideal burgués florece entre los nobles. Nobles y burgueses tienen intereses comunes y se alian para crear un programa de reformas económicas que logre acabar con el feudalismo. Pero el grupo de reformadores no pertenece, salvo raras excepciones, a la burguesía como clase social. Lo que ocurre es que tiene una mentalidad burguesa.

La poesía española del siglo xviri, antes de la epístola de "Jovino" $A$ sus amigos de Salamanca, consistía sobre todo en anacreónticas, bucólicas, idilios ${ }^{14}$. Los poetas de la escuela de Salamanca -fray Diego González, fray Juan Fernández, Iglesias, Meléndez Valdés y otrosescriben generalmente sobre temas amorosos. (Recordemos que Cadalso vivió en Salamanca y, en gran medida, actuó como corifeo del grupo). Hay, sin embargo, aun en este ambiente sensual, artificioso, arcádico, algo positivo: el redescubrimiento de las grandes tradiciones españolas que se inicia cuando los poetas vuelven los ojos a fray Luis de León, Garcilaso, Lope, y a los grandes temas poéticas del Siglo de Oro. Spell y Demerson sostienen que hay influencia de Rousseau en las descripciones de la naturaleza de Meléndez, Cienfuegos o Quintana ${ }^{15}$. Es posible. Pero parecería que donde verdaderamente se ejerce la influencia rousseauniana es en el campo de la reforma social. Las descripciones de la naturaleza de la escuela salmantina tienen como fuente primordial a fray Luis, a Garcilaso ${ }^{16}$

${ }^{13}$ Véase el magnífico artículo de Juan Manufl Herrero, "Notas sobre la ideología del burgués español del siglo xvıI", $A E A, 9$ (1952), 297-326; el libro de Luis Rodríguez Aranda, El desarrollo de la razón en la cultura española, Madrid, 1962; y V. Rodríguez CASAdo, "La revolución burguesa del xviII español", $A r b, 18$ (1951), 5-29.

14 Véase Leopoldo Augusto de Cieto, "Bosquejo histórico de la poesía castellana en el siglo xvin", introducción al t. 61 de la $B A E$, especialmente pp. cii-cl.

15 Jefrerson Rea SPeld, Rousseau and the French-Spanish world before 1833, Austin, 1938; Georges Demerson, Don Juan Meléndez Valdés et son temps, Paris, 1962 .

${ }_{16}$ En las cartas que se escriben unos a otros los integrantes de la escuela de Salamanca (apud CueTo, "Bosquejo...", passim) se habla constantemente de lecturas de estos dos poetas. 
y, claro está, a los poetas latinos. Es decir, estoy convencida de que el entronque con la tradición hispánica tiene más fuerza y mayor importancia, aquí, que la huella de Rousseau. Porque hay que insistir: el siglo xvin español redescubre a España; es un viaje al interior de la patria para exhumar sus raíces espirituales y sociales. Revaloración de las grandes fuerzas del espíritu, por un lado, y por otro el nacimiento de aquella burguesía que tímidamente había venido gestándose desde fines de la Edad Media.

Entre los ecos temáticos del Siglo de Oro está el Beatus ille. Sirvan de ejemplo unos versos de Jovellanos (Fabio a Anfriso, BAE, t. $4^{6}$, p. $\left.4^{1} b\right)$ :

dichoso el solitario penitente

... iUna y mil veces

que, triunfando del mundo y de sí mismo,

vive en la soledad libre y contento!

Unido a Dios por medio de la santa

contemplación, le goza ya en la tierra;

y retirado en su tranquilo albergue,

observa reflexivo los milagros

de la naturaleza, sin que nunca

turben el susto ni el dolor su pecho.

Regálanle las aves con su canto..., etc.

La poesía de la Ilustración está surcada de ecos y copias de poemas del Siglo de Oro ${ }^{17}$. Oigamos cómo resuenan fray Luis y Garcilaso en Jovellanos (ibid., pp. 42a, 45a):

¡Oh monte impenetrable! ¡Oh bosque umbrío!

¡Oh valle deleitoso! ¡Oh solitaria,

taciturna mansión!...

¿Oh dulces prendas, por mi mal perdidas!...

Oigamos, en este fragmento de Iglesias de la Casa, los ecos fundidos de Quevedo y del Soneto a Cristo crucificado $(B A E$, t. 61, p. $447 b)$ :

No me aterra la muerte, no rehuso

el dejar de vivir de edad florida,

ni he esquivado la muerte tan temida,

que amaneció con mi vivir confuso,

de mi cuidado asida.

Siento haber de dejar deshabitado

cuerpo que amante espíritu ha ceñido,

y yermo un corazón que tuyo ha sido,

donde todo el amor reinó hospedado

y su imperio ha extendido.

17 El propio Meléndez hace lo mismo. Véanse sus sonetos, y nótese la gran influencia de Lope y otros poetas del Siglo de Oro. Aunque se ha estudiado la resonancia de fray Luis en la poesía del xvm, falta un estudio de conjunto sobre el tema. 
No el morir siento, ¡ay Dios!, siento el dejarte: ¿qué mayor muerte quieres que perderte? Si me era paraíso y gloria el verte, ¿qué gozaré, dejando de gozarte, sino perpetua muerte?

Así, pues, parece claro que el enlace con la tradición es aquí más evidente que la influencia extranjera. Y esto explica el hecho de que los críticos (como Mérimée, o como Salinas en el caso de Meléndez) les hayan reprochado a los poetas del xvir su falta de originalidad.

Volvamos ahora al papel de Jovellanos. Joaquín Arce, que acertadamente caracteriza al escritor asturiano como "centro de irradiación de temas poéticos que enlaza el siglo xviri con el xix" y como "eje de la nota sentimental de su tiempo"18, parece, sin embargo, no caer en la cuenta de que quizá lo primordial en Jovellanos sea precisamente esa función de guía. Yo me atrevería a decir que Jovellanos cambia la faz o la dirección de la poesía del siglo xvirI.

Ya observó Ángel del Río que en Jovellanos, como en otros autores del momento, arte y erudición, poesía y ciencia social van unidas, se influyen mutuamente ${ }^{9}$. Jovellanos, hombre de Estado, economista, reformador activo, es de los primeros en observar los cambios (que él mismo fomenta). Y como sabe que para lograr ciertas reformas es preciso convencer, y por otro lado denunciar, acaba por ver en la poesía un instrumento de reforma social, un vehículo de pensamiento moral, un medio indirecto de educación. Nunca un arte puro y libre. Es curioso, sin embargo, que no haya practicado esa poesia que propugnaba, excepto en contadas ocasiones. La explicación es sencilla: Jovellanos no se consideraba poeta; se sabía hombre de Estado, jurisconsulto. Nunca pensó en publicar sus composiciones. La poesía era para él un mero pasatiempo, o bien una especie de confesión íntima que podía dar a conocer en un círculo pequeño.

En cambio, a aquellos de sus amigos que hacían "profesión de poetas", les exigía esa orientación social. Así les dice "A sus amigos

18 JoAQuín Arce, "Jovellanos y la sensibilidad prerromántica", $B B M P, 36$ (1960), 139-17\%. Sobre la poesía de Jovellanos han escrito, además, JoAQuín Alonso Bonet, La poesía de Asturias, Oviedo, 1950; Joaquín Arce, "La poesía de fray Luis de León en Jovellanos", Rev. de la Univ. de Oviedo, sept-dic. 1947, 41-55; Azorín, "Un poeta", en su libro Clásicos y modernos (1913); José Caso González, "Una sátira inédita de Jovellanos", $A O, 3$ (1953), 49-62; J. Caso González y G. Demerson, "La sátira de Jovellanos sobre la mala educación de la nobleza", $\mathrm{BH}$ i, 61 (1959), 365-386; J. DE Entrambasaguas, "La musa didáctica de Jovellanos", Rev. de la Univ. de Oviedo, 1940, núm. 4, 5-43. Cf., en general, J. Simón Díaz y J. M. Martínez Cachero, "Bibliografía de Jovellanos (1902-1950)", BIEA, 13 (1951), 131-152. Y téngase en cuenta el ya clásico estudio de César Real de la Riva, "La escuela poética salmantina del siglo xvm", $B B M P, 24$ (1948), 321-364.

19 ÁNGEL DEL Río, introducción a las Obras de Jovellanos, en Clás. cast. 
de Salamanca", hablando de sí mismo en tercera persona $(B A E, \mathrm{t}$. $4^{6}$, pp. $37 b, 3^{8 b)}$ :

$Y$ no extrañéis que del eolio canto cansada ya su musa, se convierta al compás lento y numeroso que ama tanto la didascálica poesía; que en vano de su pecho, penetrado del forense rumor, y conmovido al llanto del opreso, de la viuda y huérfano inocente, presumiera lanzar acentos dulces; ni su lira, otras veces sonora, y ora falta de los trementes armoniosos nervios, al acordado impulso respondiera. ;Ah, mis dulces amigos, cuán ilusos, cuánto de nuestra fama descuidados vivimos! $\mathfrak{i} \mathrm{Ay}$, en cuán profuncio sueño yacemos sepultados, mientras corre por sobre nuestras vidas, aguijada del tiempo volador, la edad ligera! ¿Por ventura queremos que nos tope sumidos en tan vil e infame sueño la arrugada vejez, que poco a poco se viene hacia nosotros acercando, o que la muerte pálida sepulte con nosotros también nuestra memoria? [...] ¡No, amigos, no! Guiados por la suerte a más nobles objetos, recorramos en el afán poético materias dignas de una memoria perdurable. $\mathbf{Y}$ pues que no me es dado que presuma alcanzar con mis versos alto nombre, dejadme al menos en tan noble intento la gloria de guiar por la ardua senda que va a la eterna fama, vuestros pasos.

$Y$ en el resto del poema señala Jovino a cada uno de sus amigos el camino que debe seguir: a Delio, la moral filosofía; a Batilo, el panegírico de los héroes españoles; a Liseno, la crítica de los vicios, la exaltación de la virtud y del amor patrio ${ }^{20}$. Jovellanos puede asumir

20 Hay que señalar que en esta época el concepto de "virtud" tiene un contenido social.-Ante la imposibilidad de encontrar poemas de "Liseno" (fray Juan Fernández), por el momento, analizo los de "Arcadio" (Iglesias), porque él también estuvo bajo la influencia de Jovellanos, como apunta Cueto (pp. cxiv-cxx).-Los críticos adjudican la paternidad del movimiento salmantino a diversos poetas. REAL DE LA RIVA, art. cit., considera a Cadalso como el espíritu originador; Luis Monguió, "Fray Tadeo González and Spanish taste in poetry in the I8th century”, $R R, 5^{2}$ (1961), p. 248, al P. González. Ambos críticos 
esa "gloria de guiar" los pasos de sus amigos, ya que su prestigio ante ellos es muy grande. Delio, por ejemplo, lo llama "el señor de Sevilla". Y Meléndez, que le dedica no pocos sonetos, odas y epístolas, se reconoce hechura de él $(B A E, \mathrm{t} .63, \mathrm{p} .201 a)$ :

Sí: tú volviste a mí, cuando ignorado yacía y sin vigor en noche oscura mi inculto numen, los clementes ojos con que las artes y el ingenio animas; tú extendiste la mano generosa para alzarme a la luz, y mi maestro y mi amigo y mi padre ser quisiste. Yo desde entonces, cual la tierna planta del hortelano a los desvelos crece, fruto de su cultivo y sus tareas, a sentir, a pensar por ti enseñado, obra soy tuya y de tu noble ejemplo...

A partir de la Epístola de Jovellanos, el carácter de la escuela salmantina cambia radicalmente. Antes imperaba Cadalso ${ }^{21}$, con su lirica amable o chispeante. Pero ahora se impondrá a las anacreónticas y liras el pensamiento grave, la crítica, la protesta. Delio se dedica a

tienen razón. "Delio" es el primero en acudir a las fuentes del Siglo de Oro, y es quizá quien incitó a sus compañeros a leer a los clásicos españoles. En cuanto a Cadalso, véase la nota siguiente.

21 Hay que insistir en el hecho de que la escuela de Salamanca tuvo una evolución: dejó de ser "academia cadálsica" precisamente cuando en ella comenzó a ejercer infiujo Jovellanos, propugnando sus ideas de una literatura con resonancias extra-poéticas. - La crítica de principios de siglo se había mantenido en el plano pasivo de la denuncia, posiblemente por falta de posibilidades políticas de reformar el estado de cosas. Sólo a mediados de siglo, con Ensenada, y más tarde con los integrantes del gobierno de Carlos III, hay auténticas posibilidades de cambio. Pero Cadalso, que vive este momento histórico, mantiene una mentalidad de principios de siglo. Su protesta es evasiva, utópica, como lo ha observado Rafael Segovia, Tres salvaciones del siglo xiiii español, Jalapa, 1962 (y cf. también Azorín, "Cadalso", en Lecturas españolas). Lo que ahora me interesa es destacar el papel de Jovellanos en la formación de la poesía burguesa, y dejaré para más tarde el estudio de Cadalso y otros poetas. Pero vale la pena señalar que Cadalso se dio perfecta cuenta de los temas que debían informar la poesía de su momento histórico, si bien él prefirió pulsar la cuerda amorosa. Sintió, por tanto, la necesidad de justificar su actitud. (Cf. los poemas recogidos en $B A E$, t. 61 , pp. $248-276$ ). A diferencia de Cadalso, Jovellanos quiso "ilustrar" desde la poesía, e hizo de esta tarea una "ocupación mayor", proclamando la necesidad de una literatura combativa, o burguesa, o "didáctica", como prefería decir Martínez de la Rosa (cf. su Apéndice sobre la poesía didáctica española, $B A E$, t. 15 o, pp. 57-73). V. Rodríguez Casado, "La nueva sociedad burguesa en la literatura de la época de Carlos III", $E A, 19$ (1960), 1-22, observa que la literatura de esta época suministra elementos suficientes para caracterizar el siglo xviri en sus rasgos sociales (p. 8) y habla de una "ofensiva burguesa", pero se limita a estudiar la crítica de la nobleza y de la política lugareña, y pasa por alto los temas burgueses que yo señalo. 
escribir un poema filosófico, Las edades. Iglesias continúa con su poesía satírica, y escribe El llanto de Zaragoza (1778). Batilo, por su parte, cambia de musa y comienza a elaborar lo que se conoce como su poesía "filosófica". El cambio fundamental de Meléndez ocurre hacia 1779, según lo revela su epistolario con Jovellanos. Todas las cartas anteriores a ese año (su correspondencia se inicia hacia 1776) reffejan a un Batilo indeciso, inclinado más bien a lo sentimental, y quejoso de que, por haberse dedicado a las ciencias abstractas, las musas lo han abandonado. Pero un buen día, como si de pronto abriera los ojos, escribe ( $B A E$, t. 69, p. $\left.8_{5}\right)$ :

La Castilla, la fértil Castilla, está abrumada de contribuciones, sin industria, sin artes, y poco más o menos cual la tomarían nuestros abuelos de los Alies y Almanzores. Casi todas nuestras provincias han adelantado; esta sola yace en un letargo profundo, sin dar un paso hacia su felicidad; su fertilidad misma aumenta la desidia de sus naturales, y parece que, contentos con lo que casi espontáneamente les ofrece la naturaleza, nada más apetecen, nada más piensan que se puede adelantar. La miseria es la más peligrosa de las enfermedades; ella abate el ánimo, debilita el ingenio, resfría el talento de las invenciones y degrada al hombre en todos sentidos.

No es el antiguo Batilo anacreóntico, sino el nuevo Meléndez que nos retrata Demerson (op. cit., pp. $15^{\circ}$ ss.), un Meléndez que va tomando participación activa en política y que llegará a tener un papel preponderante en la España napoleónica. Es el poeta preocupado por España, que busca soluciones concretas para sus problemas, y que traza una línea que luego continuarán Quintana y Cienfuegos. Pero ¿es verdaderamente Meléndez quien los dirige, como alguna vez se ha sostenido? Yo creo más acertado ver en Jovellanos el eje de todo el movimiento (recuérdese que Cienfuegos estudió en Salamanca y que Quintana trabajó con él en Madrid). Por otra parte, será la escuela sevillana la que continúe esta dirección burguesa en la poesía. Sevilla, aunque no es la cuna de Jovellanos, sí es su patria espiritual. En esa Sevilla que tenía desde 1697 su Real Sociedad de Medicina y demás Ciencias ${ }^{22}$, fue Jovellanos amigo de Olavide, quien le aconsejó dedicarse a las ciencias y le hizo aprender idiomas $(B A E, \mathrm{t} .46$, p. viii) - los dos renglones en que luego insistirá el asturiano al trazar el plan de estudios del Instituto de Gijón.

La poesía que comienza a escribir el grupo salmantino, dirigido por Jovellanos, y que seguirá cultivando el grupo sevillano, es poesía burguesa. (Excluyo por el momento a Forner, cuya poesía sí me parece propiamente filosófica, aunque su tono sea más bien polémico:

22 Gregorio Marañón, "Más sobre nuestro siglo xvin", ROcc, 48 (1935), 310-311. Desdevises du Dízert, L'Espagne de l'ancien régime, Paris, 1897, pp. 215-216, recuerda que la importancia de Sevilla era tal, que en tres ocasiones diversas se pensó hacerla capital de España. 
es un ir a los temas filosóficos para destruirlos, como se ve sobre todo en los Discursos sobre el hombre). El tema fundamental es la crítica social: se denuncia a la nobleza, en particular por su falta de utilidad (de tal manera que sus defensores tendrán que esforzarse por hallarle una función). Se critican los vínculos y mayorazgos que sustraen la propiedad de las tierras a la libre circulación de la economía individual. Se condena la guerra, la ambición del conquistador, el honor militar, la farsa sangrienta del guerrero. Se exalta, en cambio, el amor y la unión universales, se entonan cánticos a la fraternidad ${ }^{23}$. Se denuncia la pobreza en que vive el campesino. El campo no es ya lugar de trinos de aves, sino de miseria moral y material. El signo dominante no es ya la utopía idílica, sino la virtud sólida y concreta. El hombre virtuoso de estos poetas, el nuevo hombre exaltado por ellos hasta la hipérbole, carece, como el honnếie homme de los franceses, de las virtudes heroicas del noble o de las trascendentales del asceta o del santo, pero en cambio es productivo y tolerante. No se trata de un concepto religioso, sino social.

Joveillanos mismo utiliza todos estos temas, que no creo que sean prerrománticos, como sostienen José Caso González y Joaquín Arce, los cuales cargan demasiado el acento sobre algunas exterioridades literarias y olvidan que el prerromanticismo es ante todo una actitud política y una toma de conciencia filosófica ${ }^{24}$. Las composiciones de Jovellanos sobre el otoño, sobre la noche, sobre los coches desvencijados, su sátira Contra los letrados, sus epístolas $A$ Arnesto, $A$ Eymar, A Bermudo, A Poncio, su Respuesta a una epistola de Moratin, para citar algunos ejemplos, son poemas de tema burgués: no son poesía filosófica.. Como observa Rodríguez Casado, la Ilustración española del siglo xvin fue más actitud y postura vital que trascendencia metafísica $^{25}$. El pensamiento ilustrado es filosóficamente débil, mientras que el entusiasmo en materia pragmática y social -economía, educación, problemas de gobierno- no tiene límites. El propio Jovellanos, que tantas lecturas filosóficas ha hecho, llega a decir en su Oración inaugural del Instituto Asturiano (BAE, t. $4^{6}$, p. $\left.320 a\right)$ :

No se tratará de empeñar [al alumno] en indagaciones metafísicas, ni de hacerle vagar por aquellas regiones incógnitas donde

23 Véase Sarrailh, op. cit., cap. 4, y SÁnchez Agesta, op. cit., pp. 22-31.

21 J. ARCE, "Jovellanos y la sensibilidad prerromántica”, art. cit., sólo parece tener atención para los temas prerrománticos, y soslaya los burgueses. Véase E. Giménez Caballero, "En el centenario de Joveilanos. Su mensaje a Arnesto", REP, 1944, núm. 17, pp. 149-169, que analiza este poema, y los estudios sobre las sátiras de Jovellanos registrados supra, nota 18. - No poco debió intuir Ángel Del Río, "Jovellanos", en la Hist. general de las lit. hispánicas, t. 3, Barcelona, 1959, p. 181, al decir que Jovellanos tuvo una innegable influencia en el rumbo que tomó la poesía de su siglo.

25 V. Rodríguez Casado, "El intento español de "Ilustración cristiana»", EA, 9 (1955), 141-169. 
anduvo perdido tanto tiempo. ¿Qué es lo que puede encontrar en ellas la temeraria presunción del hombre? Desde Zenón a Espinosa y desde Thales a Malebranche, ¿qué pudo descubrir la ontología sino monstruos o quimeras, o dudas o ilusiones?

Hasta ahora se ha aceptado la denominación de "poesía filosófica" para designar toda la poesía del xviı. Propongo llamarla mejor poesia burguesa, término que corresponde más al espíritu del momento. De hecho, la única auténtica poesía filosófica de la época es casi traducción literal de Voltaire o de los ingleses (como ocurre, por ejemplo, con los poemas deístas de Meléndez Valdés).

El siglo xvirI español es pensamiento hacia el futuro. Me adhiero, así, a la interpretación de Sánchez Agesta (op. cit., pp. 240-241), que ve en esta poesía "el origen de propagación de ideas revolucionarias" en España. Observa el mismo autor cómo los temas críticos van transformando su carácter negativo y adquiriendo un contenido positivo: de los ataques contra la guerra y contra la ambición conquistadora se engendra un canto a la beneficencia y a la fraternidad; la sátira de la nobleza se eleva hasta convertirse en un himno a la igualdad; la lucha por las desvinculaciones y por la disolución de los gremios, y aun la reivindicación de las artes útiles, culminarán con la loa a la libertad. El mito de la Edad de Oro resurge, como consecuencia de una renovación social, y actúa como incentivo ideológico (ibid., p. 2422). No estoy de acuerdo, sin embargo, con Sánchez Agesta cuando observa que "a la razón crítica sucede la poesía idealizadora", y que "el transporte poético en el mundo de la intuición y el misterio ha sucedido a la claridad crítica y razonadora de principios de siglo" (ibid., pp. 249-250). Precisamente la poesía que Jovellanos impulsa es más razonadora que intuitiva, paralela a la prosa de Feijoo o de Torres Villarroel; canta el mundo de lo concreto, no el mundo de lo misterioso. Ya es significativo el hecho de que esta poesía burguesa o ilustrada se manifieste, sobre todo, en "epístolas" y "discursos", gémeros cercanos a la prosa.

Sólo nos falta ahora ver la aparición de algunos temas burgueses en la poesía de la escuela salmantina. Fray Diego González es un espíritu dulce, soñador, profundamente religioso, inseguro del camino que debe seguir, como le confiesa a Jovellanos $(B A E, \mathrm{t} .61$, pp. $198 b-199 a)$ :

Y tú, sabio Jovino $[\ldots]$, suspende un rato la tarea forense, en que te tiene sumergido el provecho común, y determina en el nuevo camino que has mostrado, mis pasos aún dudosos; lo torcido endereza $[\ldots]$.

Tuya es la idea, mío el verso solo. 
Tus doctos pensamientos ve dictando: yo al dulce verso los iré acordando.

Pero no tarda en comprender qué es lo que Jovellanos ha sugerido. Abandona, pues, la línea del Murciélago alevoso y escribe, en cambio, la Oda a las nobles artes, quizá el primer poema ilustrado, en el cual se funden los ecos de fray Luis de León con la ideología progresista del momento (ibid., pp. $185^{b-186 a)}$ :

Levanta ya del suelo

el rostro lagrimoso,

Virtud, hija del cielo, don divino [...]

Que el áspero camino

por do sigue a la gloria

y a tu morada guía,

emprenden a porfía

mil jóvenes, borrando la memoria

del vil ocio indolente

en que yaciera la española gente [...]

De la madre natura

los seres desmayados

a más sublime estado los levantas,

¡oh divina Pintura!

y al lienzo trasladados,

instruyes la razón, la vista encantas.

El pensamiento ilustrado de Delio es tímido. Ni aun lo que dejó escrito de su poema Las edades está muy definido, pero pueden observarse en él las grandes preocupaciones de la época, como cuando habla (ibid., p. 201a) de los servicios que al hombre ha prestado

\section{la inventora}

Industria, que muy breve le condujo del perizoma humilde al refulgente oro y la blanda seda, con que ahora el cuerpo cubre con soberbio lujo.

Iglesias comienza a recorrer el camino trazado por Jovellanos hacia 1778 , cuando escribe El llanto de Zaragoza. De los ejemplos de ideología burguesa que se encuentran en sus versos entresaco este fragmento de la Oda IX, muy curioso por la manera como la manoseada idea de Anacreonte " La naturaleza dio cuernos a los toros", etc.) se reviste de un vocabulario "moderno", a tono con la corriente de las luces (ibid., p. $443^{b}$ ):

La popular industria dio al hombre oficios propios con que ayudarse puedan los unos a los otros: la invención de las artes les inspiró a los doctos; 
los bélicos ardides

dio al capitán heroico;

enseñó al navegante poder surcar el ponto, $y$ al uso del viajero domar los duros potros; al labrador humilde le dio el arado corvo, y entregó al artesano

a oficios laboriosos...

Finalmente, es Meléndez Valdés quien afina las notas burguesas. Ya dijo Mérimée que los poemas inspirados en el programa burgués de Jovellanos son los mejores de Batilo ${ }^{26}$. La transición entre la primera poesía y la más madura se apunta en la epístola El filósofo en el campo. No quiero decir que Meléndez se haya convertido nunca en defensor ardiente de ideas políticas bien definidas - como es el caso de Marchena o de Quintana-, pero su poesía burguesa (me refiero exclusivamente a su poesía) si que refleja el mundo de lo concreto, los problemas reales que agobiaban a España. Esta epístola confiesa que las delicias del campo y la belleza de la vida del labriego son falsas. En varios poemas de la primera época se observa ya una especie de vacilación o dualidad: por una parte, la fuerza de la tradición literaria del Beatus ille; por otra, la comprobación de la miseria real del campesino. Así en la silva Mi vuelta al campo $\left(B A E\right.$, t. 63 , p. $\left.174^{b}\right)$ :

Aquí moran la dicha y el contento.

¡Oh campo! ;Oh soledad! ¡Oh grato olvido!

:Oh libertad feliz! Oh afortunado

el que por ti de lejos no suspira,

mas trocando tu plácida llaneza

por la odiosa grandeza,

por siempre a tu sagrado se retira!

Afortunado el que en humilde choza

mora en los campos, en seguir se goza

los rústicos trabajos, compañeros

de virtud e inocencia,

y salvar logra con feliz prudencia

del mar su barca y huracanes fieros!

Sin embargo, en esa misma silva (p. 174a) reconoce que no siempre mora la dicha en el campo, puesto que hay en él afanes y dolores:

26 E. MÉRIMÉe, “Études sur la littérature espagnole. . . : Meléndez Valdés", $R H i, 1$ (1894), p. 232: "Je préfère de beaucoup, pour ma part, les poésies, à moitié philosophiques, à moitié politiques, inspirées à Meléndez par son commerce avec Jovellanos. Ces idées de bonheur social, d'humanité, de progrès indéfini, chères aux réformateurs de l'époque, convenaient mieux à l'âme du poète, peu profonde, mais aisément ouverte aux sentiments tendres et sympathiques". 
Allí del campo hablara

con el pobre colono; y en las penas

de su estado afanoso,

con blandas voces de consuelo llenas,

humano le alentara...

Claro que este primer Meléndez no piensa en la reforma como remedio para los problemas sociales, sino que se limita a imaginar unas blandas frases de consuelo. En El filósofo en el campo los acentos son ya distintos. La parte idílica - "Aquí los dulces, los sagrados nombres / de esposo, padres, hijos, de otro modo / pronuncia el labio y suenan al oído" (ibid., p. 206a) - es más reducida, y la parte de indignación y de condena es más vigorosa: en el campo hay miseria, el labrador es triste, los niños escuálidos. Lo mismo se percibe en la epístola $A$ Llaguno (ibid., p. 202a):

Ve en él gemir al mísero colono, y al común padre demandar rendido el pan, querido amigo, que tú puedes darle, de Dios imagen en el suelo. Ve su pálida faz; llorar en torno ve a sus hijuelos y a su casta esposa. La carga ve con que espirando anhela; mísera carga, que la suerte inicua echó sobre sus hombros infelices, mientras el magnate con desdén soberbio ríe, insensible a su indigencia, y nada en lujo escandaloso y feos vicios.

En su epístola $A$ don Gaspar González de Candamo, que partía a América, se nos muestra Meléndez como partidario de los defensores de los americanos (actitud frecuente en la literatura ilustrada: piénsese en las Vidas de Quintana). Después de entonar un himno de alabanzas al "hombre natural" prosigue (ibid., p. 205a):

Mas ¡ay! si vieres al odioso fraude, al impio despotismo, el brazo alzado, sus días afligir, si a almas de hierro de su incauta bondad abusar vieres, y expilar inhumanas su miseria, ioponte denodado a estos furores!

Algo semejante se lee en la epístola La mendiguez. Aun en sus odas filosóficas hace resonar el poeta los temas burgueses: así en la Oda XII, en que habla del amor a Dios, pero también del amor a la patria. A veces el elemento burgués de crítica social es más osado. En la oda El fanatismo, Meléndez se declara contra la Inquisición; y en la oda $A$ mi patria, en sus discordias civiles, se pronuncia decididamente en contra de la guerra (ibid., p. 241 b): 
Ella en la tumba ha hundido una generación; tanta grandeza cual sombra ha fenecido; la española riqueza cebo fue del soldado a la fiereza.

El discurso La despedida del anciano (ibid., pp. 255-257) está preñado de temas burgueses: la pobreza del labrador, los aires extranjerizantes, la poca utilidad de la nobleza, la igualdad social, la educación, la utilidad de la industria. Con lúcida indignación enumera los males que aquejan a la patria (ibid., p. $257^{b}$ ):

Las leyes yacen; sucede al amor del bien la helada indiferencia; en la sangre del pobre el rico se baña. Los estados no se precian por razón; quien más estafa, es más honrado; la esteva el labrador desampara; vuela a la corte, y vilmente la libertad aldeana vende al rico, y sus virtudes con todos los vicios mancha...

El paso está dado. Después de Quintana, un Cienfuegos, un Lista, un Gallego o un Sánchez Barbero, por nombrar a los más importantes, seguirán el camino trazado ${ }^{27}$. Si todavía hay algo de "filosofismo" en Forner o en Meléndez, los más jóvenes irán desnudando su poesía de los temas abstractos y metafísicos. A la nueva generación no le preocupa la ontología, sino España, con sus lacras, sus miserias y sus posibilidades de regeneración. Quintana se interesa por igual en la vacuna y en la imprenta. (Recuérdese la importancia que la generación ilustrada concedió a la enseñanza). Las referencias a las "luces" serán más frecuentes y más precisas, y habrá menos lugar para la ensoñación. A partir de este momento, la necesidad de reforma social, de liberalización económica, entra definitivamente en la conciencia literaria del español.

IrIs M. ZAVALA

Hunter College, New York.

27 Otro maravilloso ejemplo nos lo ofrece el sevillano José María Vaca de Guzmán, a quien no he incluido en este estudio por carecer de datos precisos acerca de su vida y de sus relaciones personales. Autor de un canto épico premiado por la Academia, Las naves de Cortés destruidas (1778), dedicó también un poema a la muerte de Cadalso. Su poesía es una de las más ilustradas con que me he topado en el siglo xvm. Véanse sobre todo su poema La felicidad, enviado en ${ }_{1} 7^{81}$ a la Real Sociedad Económica de Granada $(B A E$, t. 61, pp. 287-291) y su oda El templo de la virtud (ibid., pp. 312-314). 